\title{
Direct $\mathrm{NO}_{2}$ photolysis rate monitor
}

\author{
J. O. Jackson* \\ Wayne County Health Department, Air Pollution Control Division, Detroit, Michigan 48221 \\ D. H. Stedman
}

University of Michigan, Department of Chemistry, Ann Arbor, Michigan 48104

\author{
R. G. Smith and L. H. Hecker \\ University of Michigan, School of Public Health, Department of Environmental and Industrial Health, Ann Arbor, Michigan \\ 48104
}

\section{P. O. Warner}

Wayne Country Health Department, Air Pollution Control Division, Detroit, Michigan 48221

(Received 1 November 1974; and in final form, 23 December 1974)

\begin{abstract}
An optically thin actinometer is described which measures the rate of photolysis of $\mathrm{NO}_{2}$ in air. Operating details of the device are reported together with a test in downtown Detroit. The result was that the instrument was more accurate than some of the other test parameters in the range $0-0.5 \mathrm{~min}^{-1}$. Applications to photochemical smog and stratospheric pollution problems are discussed.
\end{abstract}

\section{INTRODUCTION}

There is a general agreement ${ }^{1-3}$ that the chain-initiating reaction of photochemical smog is the photo-dissociation of $\mathrm{NO}_{2}$ by ultraviolet sunlight, where

$$
\mathrm{NO}_{2}+h_{\nu} \rightarrow \mathrm{NO}+\mathrm{O} \text {. }
$$

Kinetically, the reaction rate is expressed as

$$
R=\int_{\lambda} \phi(\lambda) I(\lambda) k_{a}(\lambda) d \lambda
$$

where $\lambda$ is the wavelength, $\phi(\lambda)$ is the quantum efficiency, $I(\lambda)$ is the intensity, and $k_{a}(\lambda)$ is the absorption coefficient of $\mathrm{NO}_{2}{ }^{4}$ We shall use $R_{1}=k_{1}\left(\mathrm{NO}_{2}\right)$, thus $k_{1}=\phi I k_{a}$. This rate has proven difficult to measure in the ambient atmosphere. ${ }^{5}$

Reaction rates of photolytic dissociations are most often determined utilizing chemical actinometry to measure quantum yields. ${ }^{6}$ Classically, liquid actinometers such as potassium ferri-oxalate are employed, where the quantum efficiency is derived from the number of ferrous ions formed per quantum absorbed. While this approach is quite appropriate for laboratory experiments, examination of photodissociative processes occurring in smog chambers or the atmosphere necessitate the use of novel instrumentation, particularly to follow the rapid changes in solar intensity. Tuesday $^{7}$ suggested the use of a pseudo-first-order rate constant, $k_{d}$, resulting from the photolysis of $\mathrm{NO}_{2}$ in pure $\mathrm{N}_{2}$, where $k_{d}=-d \ln \left(\mathrm{NO}_{2}\right) / d t$. Subsequently, Holmes $e t a l .^{8}$ have derived an expression for atmospheres not to exceed $10^{3} \mathrm{ppm}$ oxygen. Nonetheless, this method does not measure continuously and is difficult to apply in the larger smog chambers, in view of the oxygen requirement.

Recently, Stedman and Niki ${ }^{9}$ reported a smog chamber technique that determines the $\mathrm{NO}_{2}$ photolysis rate $k_{1}$ by following the buildup of photolysis products of $\mathrm{NO}_{2}$ in air.
They found that in the first few seconds of photolysis of ppm $\mathrm{NO}_{2}$ levels, the initial rate $-d\left(\mathrm{NO}_{2}\right) / d t=d\left(\mathrm{O}_{3}\right) / d t$ $=d(\mathrm{NO}) / d t=k_{1}\left(\mathrm{NO}_{2}\right)$. Rearrangement of their equation yields $k_{1}=d(\mathrm{NO}) / d t\left(\mathrm{NO}_{2}\right)=d\left(\mathrm{O}_{3}\right) / d t\left(\mathrm{NO}_{2}\right)$, and if time $\Delta t$ and $\left(\mathrm{NO}_{2}\right)$ were held constant, then, $k_{1}=C \Delta(\mathrm{NO})=C \Delta\left(\mathrm{O}_{3}\right)$, where $C=1 / \Delta t\left(\mathrm{NO}_{2}\right)$. Our instrument was based on this concept, but used a flow system for continuous measurement.

\section{EXPERIMENTAL}

To use this system as a continuous $k_{1}$ monitor, an ultraviolet transparent quartz tube was selected for a flow photolysis chamber. Such a tube permitted the establishment of regulated flows and provided for almost $4 \pi$ steradian exposure to radiant flux. The photolysis chamber shown in Fig. 1 has an inner diameter of $2.2 \mathrm{~cm}$ and is $1 \mathrm{~m}$ long. It is open at one end to allow unrestricted exhaust of unused photolysis products at atmospheric pressure. The gas entrance end is closed except for $6.35 \mathrm{~mm}$ black tubing for a gas inlet. Upstream of the photolysis tube entrance is located a rotameter to monitor the total inlet gaseous flow rate $F$. A volume flow of 4.0 liters $\mathrm{min}^{-1}$ of $1 \mathrm{ppm} \mathrm{NO}_{2}$ provided a photolysis time $\Delta t$ of $4 \mathrm{sec}$ at a distance of 70.0

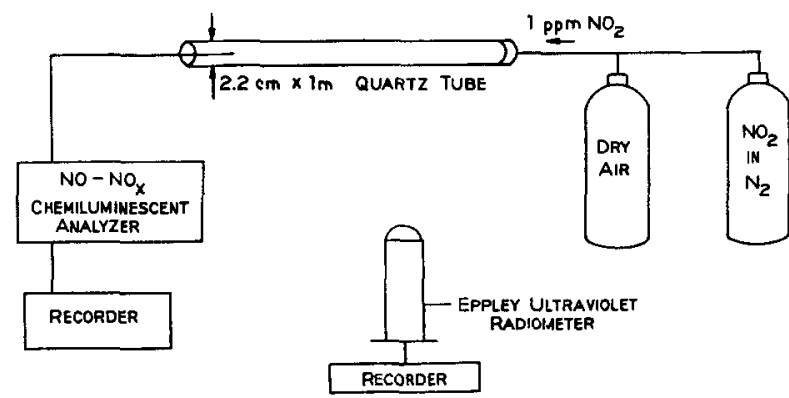

FIG. 1. A schematic diagram of the direct $k_{1}$ detector and the Eppley uv pyranometer with which it was compared. 
CALIBRATION UNIT

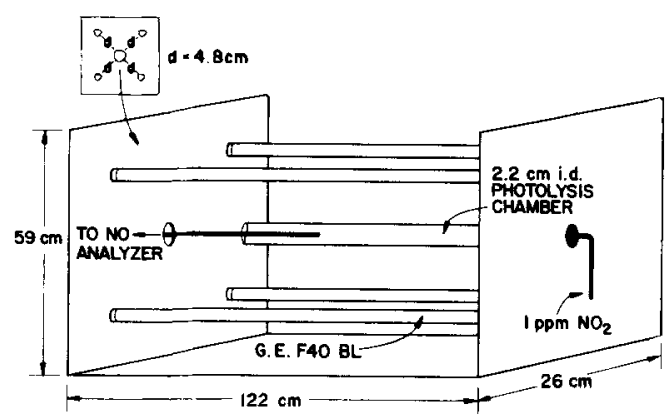

FIg. 2. Photolysis chamber for laboratory testing of the $k_{1}$ detector.

$\mathrm{cm}$. The buildup of $\mathrm{NO}[\Delta(\mathrm{NO})]$ and the initial $\left(\mathrm{NO}_{2}\right)$ was monitored with a Thermo-Electron model $12 \mathrm{~A}$ chemiluminescent analyzer altered for direct capillary inlet to the vacuum system.

Equation (1) can be rewritten under flow conditions as

$$
k_{1}=\Delta(\mathrm{NO}) /\left(\mathrm{NO}_{2}\right) \times F / A d \text {. }
$$

The total flow, $F$, is measured with the previously calibrated flowmeter, and the cross-sectional area, $A$, and flow distance, $d$, are measured directly. A good feature of Eq. (2) is that the ratio of $\Delta \mathrm{NO} / \mathrm{NO}_{2}$ is measured. This ratio is independent of the absolute calibration accuracy of the NO detector, and only depends on the linearity, and the $\mathrm{NO}_{x}$ converter efficiency, ${ }^{10}$ both readily checked.

Upstream from the inlet flowmeter is a $Y$-connection permitting the entrance of $\mathrm{NO}_{2}$ in $\mathrm{N}_{2}$ (Matheson Scientific nominally $100 \mathrm{ppm}$ ) and dry air, both from compressed gas tanks. Each cylinder was also monitored with rotameters to regulate flows, and thus the concentration of $\mathrm{NO}_{2}$ at the photolysis chamber inlet.

For experimental purposes, it was necessary to design an illumination unit to test the $k_{1}$ detector concept. While several lamp arrangements and lamp-chamber distances were evaluated, the final model selected is depicted in Fig. 2. The lamps were General Electric F40BL black lights. Although a larger number of lamps could have provided a more intense radiant flux, the four-lamp design allowed a uniform flux and approximated average $k_{1}$ values for the ambient environment.

\section{CALIBRATION}

To calibrate the photolysis chamber, a series of experiments was performed to measure $\Delta(\mathrm{NO})$ as a function of photolytic distance. The NO sampling probe was centered in the photolysis tube, with two windings of thin copper wire located near the tip of the glass capillary NO inlet. Similarly, another copper wire retainer was placed approximately $6 \mathrm{~cm}$ down the probe to aid in centering. Photolysis distances were measured using a one meter stick, and the glass capillary on the end of the NO inlet probe served to give a constant flow into the $\mathrm{NO} / \mathrm{O}_{3}$ detector reaction chamber.

A test of this device was made by measuring (NO) and $\left(\mathrm{O}_{3}\right)$ as a function of distance along the flow tube [times up to $4 \mathrm{sec}$ for various values of $\left.\left(\mathrm{NO}_{2}\right)\right]$. At 1 and $2 \mathrm{ppm} \mathrm{NO}$, linear and equal buildup of $\mathrm{NO}$ and $\mathrm{O}_{3}$ were observed, as
TABLE I. Laboratory $k_{1}$ determinations four-lamp photolysis unit.

\begin{tabular}{|c|c|c|c|c|c|c|}
\hline $\begin{array}{c}\left(\mathrm{NO}_{2}\right)_{0} \\
\mathrm{ppm}\end{array}$ & $\begin{array}{l}\text { Flow- } \\
\text { rate } \\
\text { liters } / \mathrm{min}\end{array}$ & $\begin{array}{c}\Delta(\mathrm{NO}) \\
\mathrm{ppm}\end{array}$ & $\begin{array}{c}\Delta\left(\mathrm{O}_{3}\right) \\
\mathrm{ppm}\end{array}$ & $\begin{array}{l}\text { Photolysis } \\
\text { distance } \\
\mathrm{cm}\end{array}$ & $\begin{array}{c}k_{1} \\
\min ^{-1}\end{array}$ & $\begin{array}{c}(\mathrm{NO})_{0} \\
\mathrm{ppb}\end{array}$ \\
\hline $\begin{array}{l}1.0 \\
1.0 \\
2.0 \\
2.0\end{array}$ & $\begin{array}{l}4.0 \\
4.0 \\
4.0 \\
4.0\end{array}$ & $\begin{array}{l}0.014(4) \\
0.014(2)\end{array}$ & $\begin{array}{l}0.014(0) \\
0.013(8)\end{array}$ & $\begin{array}{l}25 \\
25 \\
50 \\
50\end{array}$ & $\begin{array}{l}0.302 \\
0.295 \\
0.298 \\
0.290\end{array}$ & $\begin{array}{l}5 \\
8\end{array}$ \\
\hline
\end{tabular}

predicted. At higher concentrations of $\mathrm{NO}_{2}$ and for longer times, departures from linearity and $\mathrm{NO}$ exceeding $\mathrm{O}_{3}$ were detected, as was predicted from the work of Stedman and Niki." These experiments, which led to the choice of $4 \mathrm{sec}$ and $1 \mathrm{ppm} \mathrm{NO} \mathrm{N}_{2}$, are fully documented by Jackson. ${ }^{12}$ Table I shows one such consistency test using two concentrations of $\mathrm{NO}_{2}$ and two photolysis distances. The $(\mathrm{NO})_{0}$ values represent an initial NO impurity in the $\mathrm{NO}_{2}$, which we had to measure and use as the baseline for our $\Delta \mathrm{NO}$ measurements.

\section{AMBIENT EXPERIMENT}

This direct $k_{1}$ meter was utilized in two comparative experiments. One comparison was with $k_{1}$ calculated assuming an ambient photostationary state (PSS), where $k_{1}=k_{3}(\mathrm{NO})\left(\mathrm{O}_{3}\right) /\left(\mathrm{NO}_{2}\right)$. Stedman et al..$^{13}$ report that direct $k_{1}=0.008( \pm 0.010)+0.969( \pm 0.036)$ PSS $k_{1}$. The values in parenthesis are two standard deviations, and the correlation coefficient is 0.993 . This evidence, which was used to confirm the photostationary state assumption, also indicates the absolute accuracy of the $k_{1}$ detector.

The second comparison was with an Eppley uv pyranometer ${ }^{14}$ designed for overlap with the $\mathrm{NO}_{2}$ absorption. Figure 3 shows a trace of Eppley uv and $\Delta N O$ as a function of time, with a slight displacement for clarity. The correlation which is evident in Fig. 3 was further confirmed by plotting all measured values of $k_{1}$ vs the Eppley reading in Fig. 4. Since the Eppley detector is looking upward $(2 \pi \mathrm{sr})$ and our direct $k_{1}$ monitor measures all illumination, then some discrepancy near the origin (at low sun angle) is expected, but the rest of the correlation is excellent. The value of the correlation line was $k_{1}=0.019 \pm 0.002 \mathrm{E}$, where $\mathrm{E}$ is the Eppley reading in $\mathrm{W} \cdot \mathrm{m}^{-2}$. This correlation was obtained in Detroit for three weeks in August-September 1973.

To demonstrate that we can ignore any difficulties due to refraction and reflection in the cylindrical geometry, we rotated the tube into a range of orientations and observed

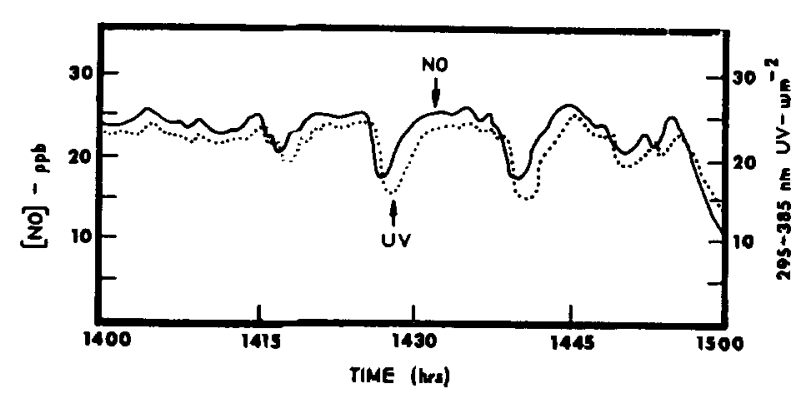

Fig. 3. The behavior of the $k_{1}$ detector and the Eppley uv meter on 26 August 1973 , from 1400 to 1500 EDT. 


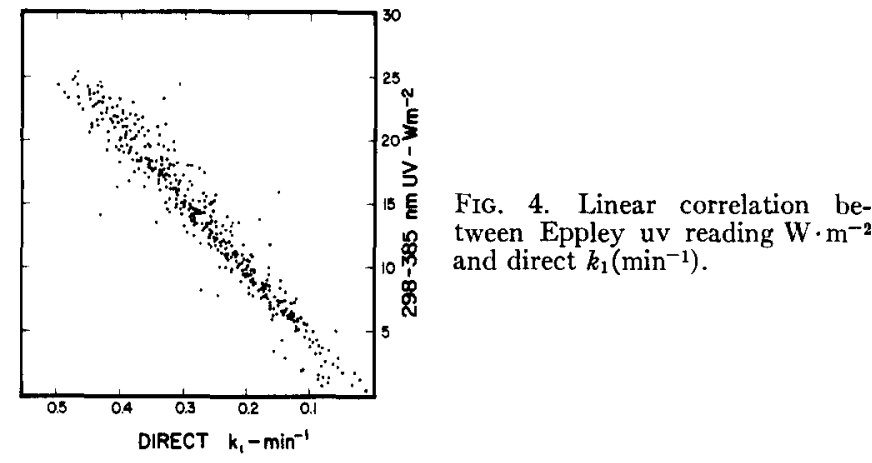

$<5 \%$ change in signal, unless the stoppered end was pointed directly at the sun.

Further studies, which we would like to perform at other latitudes, might show some small differences in the Eppley correlation, but if this relationship is well maintained, it enables a simple photometer to give values of $k_{1}$ which can be used directly in photostationary state calculations, without the need for the increased expense and experimental difficulties of the direct $k_{1}$ monitor described herein.

\section{ACKNOWLEDGMENTS}

The authors thank the director and staff of the Wayne County Health Department Air Pollution Control Division for their assistance. This work was supported in part by a NIH Training Grant No. 5T01-0H000-37, University of Michigan, School of Public Health, Department of Environmental and Industrial Health.

\footnotetext{
*Present address: Gulf Oil Corporation, Industrial Hygiene Laboratory, P. O. Box 3240, Pittsburgh, PA 15230

'A. P. Altshuller and J. J. Bufalini, Photochem. Photobiol. 4, 97 (1965).

${ }^{2}$ E. A. Schuck and E. R. Stephens, Adv. Environ. Sci. Technol. 1, 73 (1969).

${ }^{3}$ A. Kerr, J. G. Calvert, and K. L. Demerjian, Chem. Br. 8, $252(1972)$

${ }^{4} \mathrm{P}$. A. Leighton, Photochemistry of Air Pollution (Academic, New York, 1961), pp. 42-103.

${ }^{5}$ A. P. Altshuller and J. J. Bufalini, Environ. Sci. Technol. 5, 39 (1971).

${ }^{6}$ J. G. Calvert and J. N. Pitts, Jr., Photochemistry (Wiley, New York, 1966), pp. 780-786.

${ }^{7} \mathrm{R}$. D. Cadle, editor, Chemical Reactions in the Lower and Upper Almosphere (Interscience, New York, 1961), p. 15.

${ }^{8} \mathrm{~J}$. R. Holmes, R. J. O'Brien, and J. H. Crabtree, Environ. Sci. Technol. 7, 519 (1973).

'D. H. Stedman and H. Niki, Environ. Sci. Technol. 7, 735 (1973).

${ }^{10} \mathrm{R}$. K. Stevens, T. Clark, R. Baumgardner, and J. A. Hodgeson, "Instrumentation for the Measurement of Nitrogen Dioxide," ASTM Symposium on Instrumentation for Monitoring Air Quality, Boulder, CO, 1973.

${ }^{11 D}$. H. Stedman and H. Niki, J. Phys. Chem. 77, 2604 (1973).

${ }^{12}$ J. O. Jackson, Ph.D. thesis (University of Michigan, 1974).

${ }^{13}$ D. H. Stedman and J. O. Jackson, Int. J. Chem. Kinet. (to be published).

14The Eppley Laboratory, Inc., Newport, RI, ultraviolet radiometer photometer No. 12733.
} 